\title{
KUALITAS UDARA AMBIEN DI SEKITAR INDUSTRI SEMEN BOSOWA KABUPATEN MAROS
}

\author{
AMBIEN AIR QUALITY AROUND THE INDUSTRY \\ CEMENT BOSOWA DISTRICT MAROS \\ Aznaeni Duppa ${ }^{1}$, Anwar Daud ${ }^{2}$, Burhanuddin Bahar ${ }^{3}$ \\ ${ }^{1}$ Program Studi Ilmu Kesehatan Masyarakat Universitas Hasanuddin \\ ${ }^{2}$ Bagian Kesehatan Lingkungan Fakultas Kesehatan Masyarakat Universitas Hasanuddin \\ ${ }^{, 3}$ Bagian Kesehatan Kerja Fakultas Kesehatan Masyarakat Universitas Hasanuddin \\ Email Korespondensi: Aznaeni_duppa@yahoo.com
}

\begin{abstract}
ABSTRAK
Kurangnya kesadaran akan pentingnya mengelola risiko dan tidak adanya unit yang bertanggung jawab penuh terhadap risiko di cabang mengakibatkan masalah yang menghambat proses manajemen risiko. Penelitian ini bertujuan untuk evaluasi manajemen risiko kecelakaan kerja pada karyawan. Penelitian ini dilaksanakan di PT Pelabuhan Indonesia IV (Persero) Cabang Makassar. Penelitian ini merupakan penelitian observasi analitik dengan pendekatan cross sectional study. Populasi adalah keseluruhan karyawan Divisi Pelayanan Barang dan Aneka Usaha (PBAU) PT Pelabuhan Indonesia IV (Persero) Cabang Makassar. Sampel sebanyak 48 karyawan. Pengumpulan data melalui wawancara, observasi dan kuesioner. Data dianalisis secara univariat dan analisis risiko menggunakan matriks risiko berdasarkan standar AS/NZS 4360. Hasil penelitian menemukan 47 potensi bahaya. 4 potensi bahaya kategori risiko sangat tinggi, 27 potensi bahaya kategori risiko tinggi, 15 potensi bahaya kategori risiko medium dan 1 potensi bahaya kategori risiko rendah. Pengendalian risiko dengan administrative dan APD.
\end{abstract}

Kata kunci: penilaian risiko, tindakan tidak aman dan kondisi tidak aman, AS/NZS 4360

\begin{abstract}
The lack of awareness of the importance of risk managing and the absence of a unit that is fully responsible for risk in the branch produce in problems that hinder the risk management process. This study aims to evaluate the risk management of workplace accidents to employees. This research was carried out at PT Pelabuhan Indonesia IV (Persero) Makassar Branch. This research is an analytic observation research with cross sectional study approach. The population were all employees of the PT Pelabuhan Indonesia IV (Persero) Makassar Branch of Goods and Business Services Division (PBAU). The research samples were 48 employees. Data were collected through interviews, observations and questionnaires. Data were analyzed by univariate and risk analysis using a risk matrix based on AS / NZS 4360 standard. The result found there were 47 potential hazards. 4 potential hazards were very high risk categories, 27 potential hazards were high risk categories, 15 potential hazards were medium risk categories and 1 potential hazard was low risk category. Risk control by administrative and Personal Protective Equipment (PPE).

Keywords: Risk Assesment, Unsafe Actions and Unsafe Conditions, AS / NZS 4360
\end{abstract}




\section{PENDAHULUAN}

Berbagai proses alami mengakibatkan penyebaran partikel di udara seperti letusan vulkano dan hembusan debu dan tanah oleh angin. Aktifitas manusia juga menghasilkan partikel seperti partikel dari asbes bahan bangunan, abu terbang dari proses peleburan baja dan asap dari proses pembakaran yang tidak sempurna. Sumber utama partikel adalah proses pembakaran bahan bakar dan proses-proses industri (Fardiaz, 2012).

Industri semen merupakan penyumbang terbesar dari total emisi partikulat di dunia. Emisi udara dari industri semen mengandung zat-zat kimia berbahaya, seperti emisi gas rumah kaca (GRK) dan polutan gas lainnya seperti nitrogen oksida $\left(\mathrm{NO}_{\mathrm{x}}\right)$, sulfur oksida $\left(\mathrm{SO}_{\mathrm{x}}\right)$, karbon monoksida (CO) dan partikulat (Oguntoke, Awanu, \& Annegarn, 2012). Sebagian besar proses produksi pabrik semen berupa pengecilan ukuran material dan pembakaran sehingga menghasilkan emisi partikulat dalam jumlah besar, baik berasal dari emisi peralatan, aktivitas industri maupun dari kegiatan transportasi (Yhuliarsih, Sutanhaji, \& Widiatmono, 2016).

Partikel tersuspensi di udara ambien mempunyai beragam ukuran, dikelompokan menjadi TSP (Total Suspended Particel) berukuran hingga 100 mikron, PM10 (partikel dengan ukuran $<10$ mikron) dan $\mathrm{PM}_{2,5}$ (partikel dengan ukuran $<2,5$ mikron). $\mathrm{PM}_{10}$ dapat masuk dan menyebabkan iritasi dan kerusakan pada sistem pernafasan (Lestari, 2016). $\mathrm{PM}_{2.5}$ sangat berbahaya karena dapat leluasa masuk ke dalam saluran pernafasan dan mengendap di alveoli paru-paru.

Hasil penelitian udara ambien di sekitar wilayah industri semen Kota Padang, dari 10 titik, terdapat beberapa titik melebihi nilai standar baku mutu US-EPA $0,035 \mathrm{mg} / \mathrm{m}^{3}$. Titik tersebut adalah ring 2 dengan jarak $500-1.000$ $\mathrm{m}$ dari pusat pabrik dengan konsentrasi 0,041 $\mathrm{mg} / \mathrm{m}^{3}$, ring 4 dengan jarak $1.500-2.000 \mathrm{~m}$ dengan konsentrasi $0,038 \mathrm{mg} / \mathrm{m}^{3}$ dan pada ring 5 dengan jarak $2.000-2.500 \mathrm{~m}$ dengan konsentrasi $0,037 \mathrm{mg} / \mathrm{m}^{3}$ (Novirsa \& Achmadi, 2012)

Berbagai material yang terkandung di dalam $\mathrm{PM}_{2.5}$ dapat menyebabkan berbagai gangguan saluran pernafasan seperti infeksi saluran pernafasan akut (ISPA), kanker paru, penyakit kardiovaskuler, kematian dini, Penyakit paru-paru obstruktif kronis. Gangguan tersebut disebabkan oleh pembengkakan dan luka oleh pajanan $\mathrm{PM}_{2.5}$ yang masuk ke dalam saluran pernafasan dan mengendap di alveoli paru-paru.

Para ilmuwan di Kanada dan AS menemukan bahwa paparan jangka panjang terhadap $\mathrm{PM}_{2.5}$ tidak hanya secara signifikan meningkat risiko penyakit kardiopulmoner tetapi juga kematian kanker paru-paru. Penelitian yang dilakukan selama 7 tahun (dari tahun 2000- 2007) di AS menunjukkan bahwa rentang hidup ratarata diperpanjang 0,35 tahun untuk setiap penurunan $10 \mu \mathrm{g} / \mathrm{m}^{3} \mathrm{PM}_{2.5}$ (Correia et al., 2013).

Berdasarkan profil kesehatan Kabupaten Maros selama empat tahun (2014-2016), terdapat 3 penyakit gangguan pernafasan yang masuk ke dalam pola 10 penyakit utama. Penyakit tersebut 
meliputi batuk, ISPA, dan influenza. Hal ini dicurigai sebagai akibat dari kontribusi pajanan $\mathrm{PM}_{2.5}$ di udara yang dihasilkan oleh Industri Semen Bosowa sehingga perlu dilakukan penelitian tentang hal tersebut.

\section{METODE PENELITIAN}

\section{Lokasi Penelitian}

Penelitian ini dilaksanakan di sekitar wilayah Industri Semen Bosowa Kecamatan Bantimurung Kabupaten Maros yang mencakup 2 wilayah yaitu Desa Baruga dan Desa Tukamasea.

\section{Jenis Penelitian}

Penelitian ini bersifat deskriptif yang bertujuan untuk membuat gambaran atau deskripsi tentang kualitas udara ambien yaitu konsentrasi $\mathrm{PM}_{2,5}$.

\section{Sampel.}

Jumlah sampel lingkungan sebanyak 6 titik sampel udara ambien berdasarkan kelompokkelompok rumah yang berada di Desa Tukamasea dan Desa Baruga sekitar wilayah Industri Semen Bosowa Maros masing-masing 3 sampel di setiap desa. Di Desa Tukamasea, titik sampel yang ditetapkan adalah 2 titik di Dusun Bungaeja dan 1 titik Dusun Bontokappong sedangkan di Desa Baruga yaitu 1 titik di Dusun Balang, 1 titik di Dusun Batunapara dan 1 titik di Dusun Cambajawa. Metode pengambilan sampel yang digunakan yaitu secara grab sampling.

\section{Pengumpulan Data}

Pengumpulan data dilakukan dengan cara melakukan pengukuran langsung di lokasi penelitian. Sampling dilakukan untuk mengambil udara ambien dalam ukuran particular matter $<2,5$ $\mu \mathrm{m}\left(\mathrm{PM}_{2,5}\right)$, suhu, kelembaban, kecepatan angin dan jarak titik sampling ke sumber pencemar. Dalam hal ini diasumsikan bahwa sumber pencemar $\mathrm{PM}_{2.5}$ adalah pabrik dan lokasi tambang Semen Bosowa Kabupaten Maros. Pengukuran $\mathrm{PM}_{2.5}$ dilakukan menggunakan alat sampel digital direct reading Haz-Dust EPAM 5.000 USA. Alat ini menggunakan metode laser analyzer dalam melakukan pengukuran partikulat. Hasil pengukuran dapat dibaca langsung setelah pengukuran dilakukan dengan membaca nilai Time Weighted Average (TWA) sebagai nilai rata-rata.

\section{Analisis Data}

Penelitian ini dilakukan melalui beberapa tahapan kegiatan, baik dalam bentuk penelitian pustaka, pengambilan dan analisis data secara deskripsi.

Pengukuran konsentrasi $\mathrm{PM}_{2.5}$ di lokasi penelitian dilakukan hanya selama 1 jam sehingga perlu dilakukan konversi untuk memperoleh konsentrasi 24 jam agar sesuai dengan standar baku mutu. Konversi tersebut dihitung dengan menggunakan rumus model konversi canter sebagai berikut : (Hestya \& Prasasti, 2016)

$$
\mathrm{C} 1=\mathrm{C} 2\left[\begin{array}{l}
\mathrm{t}_{2} \\
-\cdots \\
\mathrm{t}_{1}
\end{array}\right]
$$

Keterangan :

$\mathrm{C}_{1}$ : Konsentrasi udara rata-rata dengan waktu pengambilan sampel selama $24 \mathrm{jam} \mu \mathrm{g} / \mathrm{m}^{3}$ 
$\mathrm{C}_{2} \quad$ : Konsentrasi udara rata-rata hasil pengukuran dengan lama pengambilan sampel selama $t_{2}$ jam

$\mathrm{t}_{1}: 24 \mathrm{jam}$

$\mathrm{t}_{2}$ : Lama pengambilan sampel (Jam)

p : Faktor konversi dengan nilai antara

0.17 dan 0.2 diambil 0.17

\section{HASIL}

\section{Konsentrasi PM 2.5}

Konsentrasi $\mathrm{PM}_{2,5}$ ambien di seluruh wilayah penelitian memenuhi syarat standar baku mutu dengan konsentrasi tertinggi pada titk 6 di Dusun Cambajawa Desa Baruga sebesar 20.92 $\mu \mathrm{g} / \mathrm{m}^{3}$. Sedangkan konsentrasi $\mathbf{P M}_{2,5}$ terendah pada titik 1 di Dusun Bungaeja 1 Desa Tukamasea sebanyak 11,30 $\mu \mathrm{g} / \mathrm{m}^{3}$ dengan konsentrasi ratarata $15,4 \mu \mathrm{g} / \mathrm{m}^{3}$.

\section{Suhu}

Suhu udara di luar rumah, dari 6 titik semuanya tidak memenuhi syarat $(100 \%)$. Suhu udara tertinggi pada titik 5 di Dusun Batunapara Desa Baruga sebesar $36,6{ }^{\circ} \mathrm{C}$ sedangkan Suhu udara terendah pada titik 3 di Dusun Bungaeja II Desa Tukamasea sebesar $33,7{ }^{\circ} \mathrm{C}$ dengan suhu udara rata-rata di kedua lokasi penelitian sebesar $35,4{ }^{0} \mathrm{C}$.

\section{Kelembaban Udara}

Kelembaban udara di luar rumah, dari 6 titik semuanya memenuhi syarat (100\%). Kelembaban udara tertinggi pada titik 2 di Dusun Bontokappong Desa Tukamasea sebesar 65,5\% sedangkan kelembaban udara terendah pada titik 1 di Dusun Bungaeja I Desa Tukamasea sebesar $48,8 \%$ dengan kelembaban udara rata-rata di kedua lokasi penelitian sebesar 55,9\%.

\section{Kecepatan Angin}

Kecepatan angin tertinggi terdapat pada titik 3 di Dusun Bungaeja II Desa Tukamasea sebesar 2,45 knot sedangkan kecepatan angin terendah terdapat pada titik 5 di Dusun Batunapara Desa Baruga sebesar 0,7 knot.

Tabel 1.

Hasil Pengukuran konsentrasi $\mathbf{P M}_{2,5}$, Suhu, Kelembaban, dan Kecepatan Angin

\begin{tabular}{cccccc}
\hline $\begin{array}{c}\text { Titik } \\
\text { Sampel }\end{array}$ & $\begin{array}{c}\mathbf{P M}_{\mathbf{2}, \mathbf{5}}\left(\boldsymbol{\mu} \mathbf{\mu g} / \mathbf{m}^{\mathbf{3}}\right) \\
\mathbf{2 4} \mathbf{~ J a m}\end{array}$ & Suhu $\left({ }^{\mathbf{O}} \mathbf{C}\right)$ & $\begin{array}{c}\text { Kelembaban } \\
(\mathbf{\%})\end{array}$ & $\begin{array}{c}\text { Kecepatan Angin } \\
(\mathbf{k n o t})\end{array}$ \\
\hline 1 & 19,4 & 11,30 & 35,1 & 48,8 & 2,2 \\
2 & 23,4 & 13,63 & 34,6 & 65,5 & 2,1 \\
3 & 25,4 & 14,80 & 33,7 & 59,9 & 2,45 \\
4 & 29,7 & 17,30 & 36,2 & 55,7 & 1,3 \\
5 & 24,7 & 14,39 & 36,6 & 55,7 & 0,7 \\
6 & 35,9 & 20,92 & 36,0 & 50,0 & 2,0 \\
\hline
\end{tabular}

\section{PEMBAHASAN}

Pengukuran Konsentrasi $\mathrm{PM}_{2,5}$, suhu, kelembaban dan kecepatan angina dilakukan pada jam 10 pagi sampai dengan jam 3 sore atau dengan kata lain, pengukuran dilakukan hanya pada siang hari. Setelah melakukan pengukuran konsentrasi $\mathrm{PM}_{2,5}$ di sekitar Industri Semen Bosowa Maros maka diperoleh nilai konsentrasi berkisar antara 20,92-11,30 $\mu \mathrm{g} / \mathrm{m}^{3}$. Dapat disimpulkan bahwa nilai konsentrasi $\mathrm{PM}_{2,5}$ di 
Duppa, 2020

udara ambien pada semua titik, tidak Selain itu, perbedaan nilai konsentrasi menunjukkan nilai yang melewati nilai standar baku mutu yang ditetapkan oleh US-EPA yaitu 35 $\mu \mathrm{g} / \mathrm{m}^{3}$.

Hasil pengukuran tersebut berbeda dengan hasil pengukuran di Kawasan Industri Semen di Kota Padang (Novirsa \& Achmadi, 2012b). Di Kota Padang terdapat tiga titik yang melebihi standar baku mutu. Konsentrasi $\mathrm{PM}_{2,5}$ tertinggi di Maros sebesar 20,92 $\mu \mathrm{g} / \mathrm{m}^{3}$ sedangkan di Kota Padang sebesar $41 \mu \mathrm{g} / \mathrm{m}^{3}$.

Rendahnya konsentrasi $\mathrm{PM}_{2,5}$ ambien di sekitar Industri Semen Bosowa Maros dimungkinkan karena lingkungan di sekitar wilayah tersebut masih banyak terdapat tutupan lahan hijau dan kondisi geografis di sekitar daerah tersebut berupa perbukitan sehingga $\mathrm{PM}_{2,5}$ dapat berkurang ke sekitar pemukiman masyarakat. $\mathrm{PM}_{2,5}$ akan mengendap pada daun-daun tanaman sehingga akan berkurang jumlahnya ke pemukimam masyarakat.

Selain itu, diketahui bahwa saat penelitian ini dilakukan, PT Semen Bosowa Maros hanya mengoperasikan 1 mesin saja sehingga produksi berkurang dari biasanya sehingga turut pula mengurangi $\mathrm{PM}_{2,5}$ yang dihasilkan. Berkurangnya kemampuan produksi turut menurunkan kegiatan tambang bahan baku semen, pengangkutan bahan baku dan besarnya pengolahan bahan baku menjadi semen. Hal ini sangat mempengaruhi polutan yang dihasilkan karena kegiatan tersebut merupakan kegiatan yang banyak menghasilkan polutan $\mathrm{PM}_{2,5}$. $\mathrm{PM}_{2,5}$ yang diukur dapat juga dipengahuri oleh waktu pengambilan sampel yang dilakukan pada siang hari. Pada siang hari suhu di permukaan bumi lebih cepat panas dibandingkan beberapa ratus meter di atasnya. Suhu ini akan menurun pada setiap ketinggian 100 meter sebesar $1{ }^{\circ} \mathrm{C}$. Hal ini menyebabkan polutan yang dihasilkan oleh cerobong dan daerah peledakan akan melayang untuk beberapa ratus meter. Polutan akan turun ke permukaan bersuhu lebih tinggi dan bertekanan lebih rendah. Siklus ini terus berlanjut hingga beberapa ribu meter sampai polutan terdispersi dengan merata. Karena hal tersebut $\mathrm{PM}_{2,5}$ bisa Mencapai daerah yang lebih jauh. Suhu udara di lokasi penelitian berkisar antara 33,7$36,6{ }^{\circ} \mathrm{C}$

Partikel debu pada suhu yang tinggi akan mengendap lebih lambat dibandingkan pada suhu yang lebih rendah. Hal ini disebabkan karena suhu tinggi menyebabkan udara makin renggang sehingga konsentrasi polusi udara menjadi semakin rendah. Pada suhu yang tinggi partikel debu akan lebih ringan, sehingga akan lebih lama berada di udara dalam keadaan turbulen. Sementara pada suhu rendah partikel akan lebih berat dan lebih cepat mengendap sehingga partikel debu yang terhisap oleh alat lebih sedikit.

Kelembaban udara turut berperan dalam besaran jumlah $\mathrm{PM}_{2,5}$ yang ada di udara. Kelembaban berhubungan dengan kecepatan mengendap partikel debu Kondisi udara lembab membantu proses pengendapan bahan pencemar. Partikel debu lebih cepat mengendap 
pada kelembaban tinggi dibandingkan dengan kelembaban rendah (Misriani, 2015). Udara lembab menyebabkan partikel berikatan dengan air yang ada di udara dan membentuk partikel berukuran lebih besar sehingga mudah mengendap kepermukaan bumi oleh gaya tarik bumi.

Kecepatan angin mempengaruhi distribusi polutan. Konsentrasi polutan akan berkurang jika angin kencang dan membagikan polutan secara mendatar atau tegak lurus. $\mathrm{PM}_{2,5}$ berukuran sangat kecil sehingga mudah terbawa angin. Kecepatan angin yang kuat akan membawa polutan terbang ke mana-mana sehingga mencemari udara di tempat lain. Sebaliknya apabila kecepatan angin lemah, polutan akan menumpuk dan dapat mencemari udara tempat bermukim di sekitar lokasi pencemaran tersebut. Dari hasil pengukuran terlihat bahwa kecepatan angin berkisar antara 0,7-2 knot.

Pengukuran sampel dilakukan pada awal bulan Mei dimana hingga akhir Bulan April curah hujan masih tinggi. Hal ini juga dapat mempengaruhi jumlah konsentrasi polutan. $\mathrm{PM}_{2,5}$ yang terkena air hujan akan ikut dengan aliran hujan. Hal ini menyebabkan $\mathrm{PM}_{2,5}$ di udara akan berkurang atau bahkan tiak ada lagi.

\section{KESIMPULAN DAN SARAN}

Berdasarkan hasil pengukuran yang dilakukan maka dapat disimpulkan bahwa konsentrasi $\mathrm{PM}_{2.5}$ masih dibawah standar baku mutu yang ditetapkan oleh EPA $\left(35 \mu \mathrm{g} / \mathrm{m}^{3}\right)$.
Walaupun masih dibawah standar baku mutu namun, tetap perlu dilakukan upaya-upaya untuk mempertahankan kondisi tersebut sehingga tidak akan menimbulkan masalah kesehatan bagi masyarakat.

\section{DAFTAR PUSTAKA}

Correia, A. W., Pope III, C. A., Dockery, D. W., Wang, Y., Ezzati, M., \& Dominici, F. (2013). The effect of air pollution control on life expectancy in the United States: an analysis of 545 US counties for the period 2000 to 2007. Epidemiology (Cambridge, Mass.), 24(1), 23.

Dinkes. (2014). Profil Kesehatan Kabupaten Maros Tahun 2014. Maros: Dinas kesehatan kabuapten maros.

Dinkes. (2015). Profil Kesehatan Kabupaten Maros Tahun 2015. Maros: Dinas kesehatan Kabupate Maros.

Dinkes. (2016). Profil Kesehatan Kabupaten Maros Tahun 2016. Maros: Dinas kesehatan Kabupaten Maros.

Fardiaz, S. (2012). Polusi Air \& udara. Yogyakarta: Kanisius

Hestya, I., \& Prasasti, C. I. (2016). Environmental Health Risk Factor in the Community Around of Rejo Agung Baru Sugar Factory Madiun. Jurnal Kesehatan Lingkungan, 8(1), 81-91.

Misriani. (2015). Penilaian Konsentrasi Partikulat Matter (PM10) dan PM 2,5) Di Sekolah Dasar. Universitas Hasanuddin, Makassar.

Novirsa, R., \& Achmadi, U. F. (2012). Analisis Risiko Pajanan PM2, 5 di Udara Ambien Siang Hari terhadap Masyarakat di Kawasan Industri Semen. Kesmas: National Public Health Journal, 7(4), 173-179. 
Duppa, 2020

Oguntoke, O., Awanu, A. E., \& Annegarn, H. J. (2012). Impact of cement factory operations on air quality and human health in Ewekoro Local Government Area, South-Western Nigeria. International journal of environmental studies, 69(6), 934-945.

Yhuliarsih, E., Sutanhaji, A. T., \& Widiatmono,

B. R. (2016). Analisis Sebaran Beban

Partikulat secara Keruangan dari Industri

Semen di Kabupaten Tuban. Jurnal

Sumber Daya Alam dan Lingkungan, 2(3), 40-48 